\title{
Atlas of Urologic Clinics of North America: Treatment of Benign Prostatic Hyperplasia
}

Prostate Cancer and Prostatic Diseases (2003) 6, 198. doi:10.1038/sj.pcan.4500660

Edited by M Cabelin \& S Kaplan

WB Saunders: New York, April 2002

This book contains a collection of articles outlining the treatment of benign prostatic hyperplasia (BPH). The authors of each section review a particular treatment option for 'symptomatic BPH'. Indeed, the intention of the book is to 'outline what is available today'. However, in fact, the chapters cover an introduction to the anatomy and physiology and an assessment of the condition, but thereafter only cover techniques or devices and there is no discussion of drug treatment. Despite this, there are nice reviews of many of the treatment options that have been explored over the last 15 years. There is nothing here that is particulary novel, but this book will serve as an convenient repository of information about most of the techniques available with a reasonable review of the literature for each. Therefore, it provides a convenient 'snapshot' of what is available and is readable, concise, elegant and well illustrated and is produced in a larger format of the otherwise familiar Urological Clinics of North America style. I am not sure who the book is aimed at. The editors hoped the volume would be 'provocative, informative and ultimately applicable' in urologists practice. I suspect it will be a useful introduction for Trainees and Residents and does have the great advantage of including detailed descriptions of the tranditional open surgery, which is so little seen now by our Trainees. I think it would be a useful addition to a departmental library as the chapters provide an introduction, at least, to many procedures and devices currently being evaluated for the management of 'symptomatic BPH'. There are few minor errors but the overall quality of production is excellent.

Tom A McNicholas

\section{Corrigendum}

\section{Coxsackie $B$ and adenovirus receptor, integrin and major histocompatibility complex class 1 expression in human prostate cancer cell lines: implications for gene therapy strategies}

\author{
HS Pandha, LH Stockwin, J Eaton, IA Clarke, AG Dalgleishm, SM Todryk \& GE Blair
}

Prostate Cancer and Prostatic Diseases (2003) 6, 198. doi:10.1038/sj.pcan.4500661

Correction to: Prostate Cancer and Prostatic Diseases (2003) 6, 6-11. doi:10.1038/sj.pcan.4500661

In the above paper, the source of the cells used for the experiments were not fully acknowledged. With reference to the materials and methods section under 'cell lines', text should read 'Cell lines P4E6' (Maitland NJ, Mackintosh CA, Hall J, Sharrad M, Quinn G, and Lang S, In vitro models to study cellular differentiation and function in human prostate cancer cells. Radiat Res 2001; 155: 133-142), ShMac-1, ShMac-4 and ShMac-5 were developed by the Yorkshire Cancer Research Centre Unit at the University of York (Professor Norman Maitland). 